\title{
Isolation of T-Mycoplasmas from Goats, and the Production of Subclinical Mastitis in Goats by the Intramammary Inoculation of Human T-Mycoplasmas
}

\author{
By R. N. GOURLAY, J. BROWNLIE AND C. J. HOWARD \\ ARC Institute for Research on Animal Diseases, \\ Compton, Newbury, Berkshire
}

(Received 23 November 1972)

\section{INTRODUCTION}

T-Mycoplasmas have been isolated from the human urogenital tract (Shepard, 1954) and oropharynx (Taylor-Robinson \& Purcell, 1966). They have also been isolated from the urogenital tract of cattle (Taylor-Robinson, Haig \& Williams, 1967), from pneumonic calf lungs (Gourlay, 1968), from eyes in cases of bovine keratoconjunctivitis (Gourlay \& Thomas, 1969), from the throats of cats (Tan \& Markham, 1971), from the genital tract of dogs and the throats of squirrel monkeys (Taylor-Robinson, Martin-Bourgon, Watanabe \& Addey, 1971).

T-Mycoplasmas have been implicated not only in non-specific urethritis in man (Ford, Rasmussen \& Minken, 1962; Csonka, Williams \& Corse, 1966), but also in abortions and premature births in women (Knudsin, Driscoll \& Ming, 1967). However, there is still doubt about their aetiological significance in these conditions. The assessment of their role in human disease has been hampered to a large extent by the lack of a suitable experimental animal.

In earlier studies we showed that certain bovine $\mathrm{T}$-mycoplasmas inoculated via the teat canal into the mammary glands of cows could produce mastitis, whereas six human T-mycoplasmas similarly inoculated did not (Gourlay, Howard \& Brownlie, 1972; Howard, Gourlay \& Brownlie, 1973). We also showed that a strain of bovine T-mycoplasma was capable of causing mastitis in goats, indicating that host specificity was not absolute (Howard et al. 1973).

In view of these results, we decided to investigate whether goats harbour T-mycoplasmas and also whether human T-mycoplasmas could infect the caprine mammary gland, with a view to its use for assessment of pathogenic effects of human T-mycoplasmas.

\section{METHODS AND RESULTS}

\section{Isolation of T-mycoplasmas from goats}

Four adult female goats were examined for the presence of T-mycoplasmas. A cottonwool swab was inserted up both nostrils and another swab was inserted into the vagina and the external urethral opening of each goat. The swabs were then placed into $2 \mathrm{ml}$ of GS broth (Gourlay \& Leach, 1970) at neutral pH. After a few minutes the swabs were removed and from each broth three series of tenfold dilutions were made in (i) further GS broth, at $\mathrm{pH} 7 \cdot 8$, (ii) U2 broth (U broth, Gourlay et al. 1972, minus hepes buffer but containing $0.05 \%$ urea and $15 \%(\mathrm{v} / \mathrm{v})$ foetal calf serum), and (iii) arginine-containing broth (Gourlay, 
Mackenzie \& Cooper, 1970). All broths were incubated at $37^{\circ} \mathrm{C}$. No colour change was observed in any of the arginine broth dilutions, nor in the GS broth dilutions from the urogenital tracts. However, colour change was observed in the GS broth dilutions from the noses of two goats indicating the presence of glucose-fermenting organisms. No colour change was seen in the $U_{2}$ broths from the nasal passages, but after 3 days of incubation an alkaline colour change was observed in the $10^{-1}$ dilution of the $\mathrm{U}_{2}$ broth titrations from the urogenital tract swabs from three of the goats. The agents causing this colour change were subcultured a number of times by further tenfold dilutions in $\mathrm{U}_{2}$ broth and eventually drops of culture were placed on solid medium plates [tryptone, $\mathrm{I} \cdot 7 \% \mathrm{w} / \mathrm{v}$ (Oxoid, London); neutralized soya peptone, 0.3\% (Oxoid); Hanks BSS, 40\%, v/v (Wellcome Research Laboratories, Beckenham, Kent); hepes, $0.05 \mathrm{M}$ (Sigma, London); foetal bovine serum, $20 \%$, v/v (Flow Laboratories, Irvine, Scotland); Agarose, $0.9 \%$, (Miles-Seravac, Maidenhead, Berkshire); penicillin, I000 u/ml; thallium acetate, $0.025 \%$; phenol red, $0.0025 \%$, $\mathrm{pH}$ 6.2]. After incubation at $37^{\circ} \mathrm{C}$ under $5 \% \mathrm{CO}_{2}$ in $\mathrm{N}_{2}$, typical T-mycoplasma colonies were observed.

\section{Intramammary inoculation of goats with human T-mycoplasmas}

Eleven lactating goats, I to 2 years of age, were inoculated via the teat canal with $10 \mathrm{ml}$ of actively growing T-mycoplasma cultures. The number of T-mycoplasmas and the number of cells present in milk were measured as previously described (Gourlay et al. 1972; Howard et al. 1973). T-Mycoplasmas were not isolated from the milk before inoculation. Six human T-mycoplasma strains were used: they were CD342 (T960), CD343 (Johnson), CD408, CD573, MI26/68 and M267. The first four were kindly supplied by Dr D. TaylorRobinson, Clinical Research Centre, Harrow, Middlesex, and the last two by Dr B. E. Andrews, Mycoplasma Reference Laboratory, Central Public Health Laboratory, Colindale, London.

The CD573 strain (titre $10^{6.0}$ to $10^{6.7} / \mathrm{ml}$ ) was inoculated into the left gland and $\operatorname{CD} 408$ (titre $10^{5.7}$ to $10^{6} / \mathrm{ml}$ ) strain into the right gland of each of four goats. One gland of a further goat was also inoculated with the CD573 strain and one gland of two other goats with the CD408 strain.

Four of the five glands inoculated with the CD573 strain produced only a transient cell response in the milk and T-mycoplasmas were isolated only on the first and second days after inoculation. The fifth gland produced an initial transient cell response and T-mycoplasmas were isolated on days I and 2 after inoculation. However, a second response commenced on day 9: a gradually increasing cell response was observed which reached a peak on day 30 and then began to fall. T-Mycoplasmas were isolated daily from day 9 and the titre reached a peak of $10^{6.0}$ organisms $/ \mathrm{ml}$ of milk on day 16 , thereafter falling gradually to $10^{1.7}$ organisms $/ \mathrm{ml}$ on day 33 when the experiment was terminated.

Two of the six glands inoculated with the CD408 strain produced only a transient cell response and T-mycoplasmas were isolated from the milk on days I and 2 only. The other four glands, however, reacted more severely. An initial transient cell response lasting 3 to 4 days and isolation of T-mycoplasmas on days I and 2 was followed by a second response. This began between days 4 and 8 and was made manifest by an increased cell response which persisted until the experiment was terminated on day 33. T-Mycoplasmas were again isolated from the milk. The titre increased rapidly in two cases to reach a peak of $10^{6.0}$ and $10^{5.7}$ organisms $/ \mathrm{ml} 7$ and 13 days after inoculation and then fell slowly to $10^{4.7}$ and nil by the end of the experiment. In the other two cases the titre increased gradually to reach a peak, in one case of $10^{6.0}$ organisms/ml by day 28 at which level it remained until 

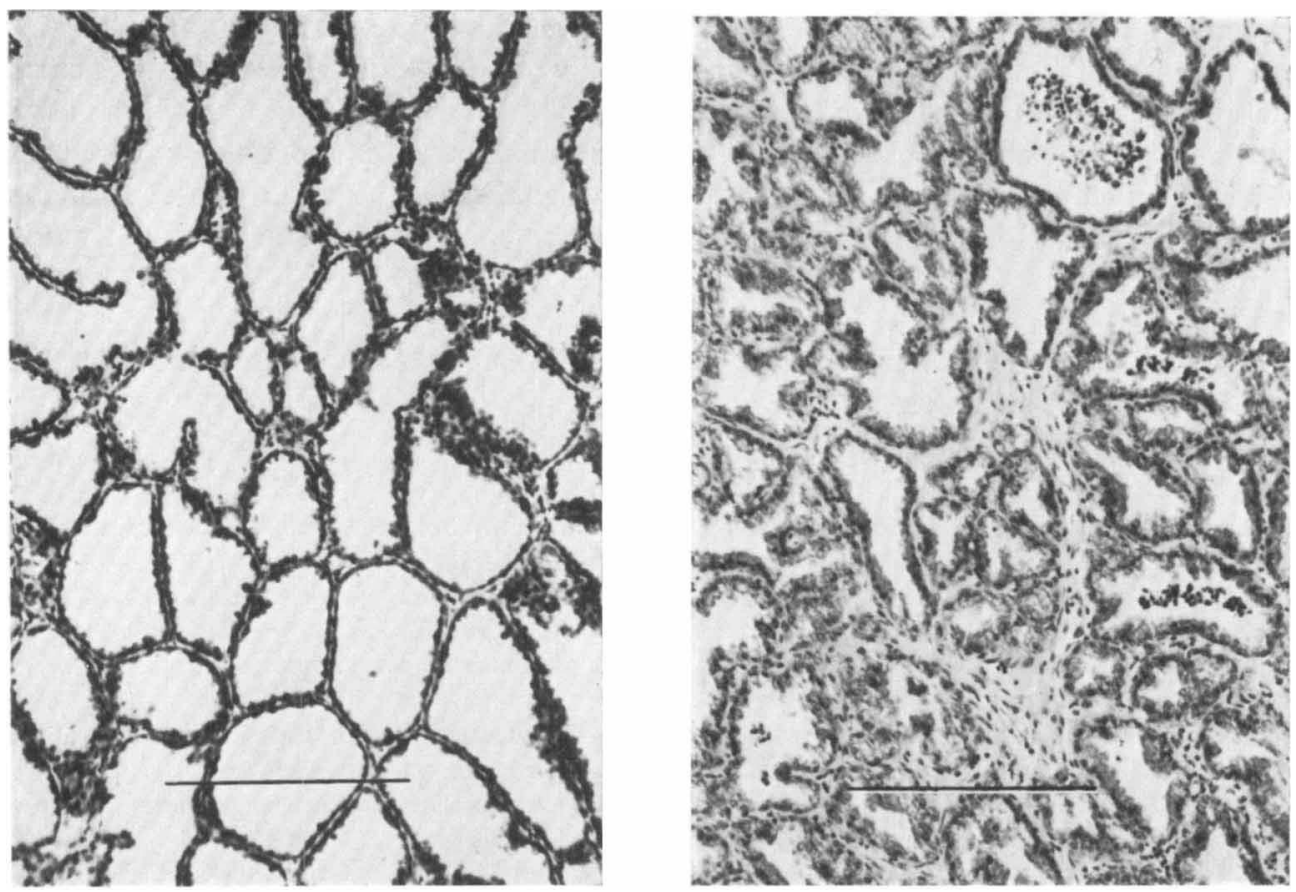

Fig. I (a) Section of uninoculated mammary gland with extended acini and normal secretory epithelium. Stained haematoxylin and eosin. Bar marker represents $250 \mu \mathrm{m}$. (b) Section of mastitic gland with marked increased interacinar cellularity, neutrophils intraluminally and early evidence of involution. Stained haematoxylin and eosin. Bar marker represents $250 \mu \mathrm{m}$.

the experiment was terminated, and in the other case $10^{5.0}$ organisms $/ \mathrm{ml}$ on day $\mathrm{I} 5$ when the goat was killed. Portions of mammary tissue from this last goat were taken at autopsy for histopathological examination and showed a markedly increased interacinar cellularity with neutrophils intraluminally and early evidence of involution (Fig. I).

T-Mycoplasma strains CD342, CD343, MI26/68 and M267, at titres between $10^{5.0}$ and $10^{7.0}$ organisms $/ \mathrm{ml}$, were inoculated into four goats; the injections were so arranged that each of the four strains was inoculated into one gland of each of two different goats. None produced a significant cell or T-mycplasma response in the milk.

\section{DISCUSSION}

T-Mycoplasmas were isolated from the urogenital tract of three out of four goats. A number of other mycoplasma species have been isolated from goats but this is the first report of the isolation of T-mycoplasmas. These new caprine isolates have not yet been tested for pathogenicity. However T-mycoplasmas have been isolated from several other hosts - in particular man, where they have been implicated in urogenital disease.

Strains of T-mycoplasmas isolated from man did not produce mastitis in the bovine mammary gland (Gourlay et al. 1972; Howard et al. 1973). In the goat mammary gland, however, certain of these human strains produced a subclinical mastitis. No gross milk changes were observed, but a cellular response occurred in the gland as estimated by cell 
counts performed on the milk samples, and in one case by histopathological evidence and furthermore T-mycoplasmas were excreted at relatively high titre for a prolonged length of time. There is no doubt that $\mathrm{T}$-mycoplasmas actually multiplied in the glands of the goats in view of the large total quantity of milk produced by the goats during the course of the experiment and the consistently high titre of organisms excreted in the milk compared with the initial inoculum. Our results suggest that the goat could be a suitable experimental animal for studying the pathogenicity of human T-mycoplasma strains, particularly using the mammary gland.

We would like to than Mrs M. Gleed, Miss E. A. Coleman, Miss J. Wren and Miss S. G. Wyld for technical assistance.

\section{REFERENCES}

CsonKA, G. W., Williams, R. E. O. \& CoRSE, J. (1966). T-strain mycoplasma in non-gonococcal urethritis. Lancet, I 292-1296.

FoRD, D. K., RASMUSSEN, G. \& MINKEN, J. (1962). T-strain pleuropneumonia-like organisms as one cause of non-gonococcal urethritis. British Journal of Venereal Diseases 38, 22-25.

Gourlay, R. N. (1968). The isolation of T-strains of mycoplasma from pneumonic calf lungs. Research in Veterinary Science 9, 376-378.

Gourlay, R. N., Howard, C. J. \& Brownlie, J. (1972). The production of mastitis in cows by the intramammary inoculation of T-mycoplasmas. Journal of Hygiene 70, $5 \mathrm{II}-52 \mathrm{I}$.

GouRLAY, R. N. \& LEACH, R. H. (1970). A new Mycoplasma species isolated from pneumonic lungs of calves (Mycoplasma dispar sp. nov.). Journal of Medical Microbiology 3, I I I-I 23.

Gourlay, R. N., MACKenzie, A. \& CoOper, J. E. (1970). Studies of the microbiology and pathology of pneumonic lungs of calves. Journal of Comparative Pathology 8o, 575-584.

Gourlay, R. N. \& Thomas, L. H. (1969). The isolation of large colony and T-strain mycoplasmas from cases of bovine kerato-conjunctivitis. Veterinary Record 84, 4I6-4I7.

Howard, C. J., Gourlay, R. N. \& Brownlie, J. (I973). The virulence of T-mycoplasmas, isolated from various animal species, assayed by intramammary inoculation of cattle. Journal of Hygiene (in the Press).

KNudsin, R. B., Driscoll, S. G. \& Ming, P. L. (1967). Strain of Mycoplasma associated with human reproductive failure. Science, New York 157, 1573-I 574.

SHEPARD, M. C. (1954). The recovery of pleurcpneumonia-like organisms from Negro men with and without non-gonococcal urethritis. American Journal of Syphilis, Gonorrhea and Venereal Diseases 38, I I 3-124.

TAN, R. J. S. \& MARKham, J. G. (1971). Feline T-strain mycoplasmas. Japanese Journal of Experimental Medicine 4I, 247-248.

Taylor-Robinson, D., Haig, D. A. \& Williams, M. H. (1967). Bovine T-strain mycoplasma. Annals of the New York Academy of Science $\mathbf{1 4 3}, 517-518$.

Taylor-Robinson, D., Martin-Bourgon, C., Watanabe, T. \& Addey, J. P. (1971). Isolation of T-mycoplasmas from dogs and squirrel monkeys: biological and serological comparison with those isolated from man and cattle. Journal of General Microbiology 68, 97-107.

Taylor-Robinson, D. \& Purcell, R. H. (I966). Mycoplasmas of the human urogenital tract and oropharynx and their possible role in disease: a review with some recent observations. Proceedings of the Royal Society of Medicine 59, I I 12-11 16. 